Pedro Trigo, S.J.

Profesor Instituto de Teología para Religiosos (ITER)

\title{
Teólogos no profesionales laicos
}

\section{LOS SUJETOS QUE HAN HECHO TEOLOGÍA A LO LARGO DE LA HISTORIA}

Habría que comenzar diciendo que los primeros teólogos fueron laicos. Los nombres de Justino, Clemente, Orígenes y Tertuliano ilustran lo que queremos decir. Hasta mediados del siglo IV el cristianismo aparecía a los ojos de la gente culta como una propuesta demasiado poco formalizada, sistematizada y fundamentada, demasiado ligada a unos acontecimientos particulares y a unos ritos excesivamente aledaños a la cotidianidad, poco ritualizados y autorizados. Algo más bien factual, comunitario y voluntarioso, propio de gente de buena voluntad, con gran empuje interior y capacidad de atracción; una propuesta sana y provechosa para mucha gente a quien le resultaba radicalmente insuficiente la religión cívica y política, demasiado formalista, y por eso poco personal y religiosa, lo mismo que las religiones de los misterios, que apelaban a una experiencia numinosa y transformadora, que se revelaba incapaz de cumplir lo que prometía. Sin embargo, la participación en la gran Iglesia, si satisfacía dimensiones religiosas, comunitarias y éticas de la persona, resultaba muy insuficiente como formulación rigurosa. Con dificultad podía dar cuenta de sí y su visión aparecía como rudimentaria, tanto en la forma de expresarse como en el vuelo de sus elaboraciones. Por eso, entre otras causas, tuvo tanta penetración la gnosis en los círculos cultivados. En un sentido meramente formal se puede decir que la primera teología (como el concepto de espiritualidad) es la gnóstica. Este ambiente está presente en el cuarto evangelio y de ahí su aceptación o, por mejor decir, su aprovechamiento por las sectas.

Esto es lo que mueve a los alejandrinos a fundar una verdadera escuela, en el sentido en que funcionaban en las ciudades helenistas. Muy claramente ese es el desafío que tiene ante sí Orígenes, que, no en balde, fue durante largos años alumno esotérico de Ammonio Saccas y tuvo como condiscípulo nada menos que a Plotino. Orígenes, el escritor más prolífico de la antigüedad, poseía las herramientas técnicas y la organización mental de las personas cultas, y más específicamente de los filósofos de su tiempo, que eran en gran medida hermeneutas. Pero la teología no fue para él verter el misterio cristiano en esos moldes. Escribir teología fue para él una empresa mucho más creativa. Él había sido iniciado en el misterio cristiano desde su infancia por su padre, que murió mártir. El misterio no era para él un espíritu sin forma, un estilo de vida sin teoría, una comunidad humana sin constitución. Para él el misterio cristiano estaba concentrado en Jesús de Nazaret, que era el revelador 
personal de Dios y el paradigma de vida humana. Ser cristiano era vivir en comunión con él, y a través de él, con su Dios. Y todo esto se realizaba en el seguimiento y se celebraba en la comunidad. Pero el medio por el que se conocía internamente el misterio cristiano era la Biblia. El cristianismo era una religión del libro. En ella y solo en ella podía encontrarse el mito cristiano, para decirlo en términos platónicos. Todo lo que él escribió fue glosa de la Biblia. Pero la Biblia, como libro sagrado que era, debía interpretarse, como los filósofos helenistas interpretaban sus libros sagrados. De ahí su teorización de los distintos sentidos de la Biblia y sobre todo su manejo de ellos como herramientas que permiten que el texto dé de sí y no como quienes imponen su lógica al texto, cosa que sí sucedía en la interpretación alegórica de los mitos de Homero y Hesíodo.

Para Orígenes, como para Clemente y Tertuliano y antes para Justino, la teología es un saber de fe y tiene el carácter de exigencia de la misma fe, que, como se dirá luego, busca entender, una exigencia, pues, personal del creyente, pero no menos una contribución para la misión, ya que se trataba de decir el Evangelio en las coordenadas de su tiempo, de la cultura letrada de su tiempo; por eso la tendencia a la alegoría de los alejandrinos se convierte en rigor jurídico en el cartaginés romanizado que era Tertuliano. Así pues, lo sustantivo no era para ellos esa cultura de la que participaban, a la que enriquecían con esos aportes cristianos. Ellos se definían como cristianos. Por eso hacer teología no era para ellos un juego de ingenio o un servicio pedagógico; era una obediencia a la fe. Por eso para ellos, a diferencia de los gnósticos, en su tarea intelectual hay siempre entrañada una preocupación por la fidelidad. Ellos tienen claro que la única fidelidad posible es la creativa, pero su creatividad buscará empeñosamente ser fiel.

Su elaboración teológica será para ellos sin duda una labor eclesial: así como son cristianos en la Iglesia, así en ella hacen teología. Pero no piden permiso a nadie para hacerla. La exponen públicamente como su servicio. Naturalmente que no tienen pretensiones de infalibilidad y por eso se coordinan con el servicio del obispo; pero entienden que ese servicio suyo es también su carisma, no solo para la Iglesia sino también para los que están fuera y quizás por la mediación de su ministerio, podrán llegar un día a estar dentro o por lo menos a no estar opuestos.

Hay que decir que los teólogos eclesiásticos que vinieron después no trataron a estos teólogos con la misma benevolencia con que trataron a sus colegas. Es cierto que cometieron errores, pero es que estaban codificando lo no codificado y no podían proceder sino por tanteos, por ensayo y error. Estaban creando un género, y la teología, como cualquier saber, no puede nacer ya adulta y plenamente formada. Incluso los más grandes de los que vinieron después, cuando ya estaba roturado el suelo, escribieron errores. Creemos, pues, que en ese trato influyó que no eran de los suyos, que no eran representantes de la institución.

Porque después de estos cabezas de fila laicos vinieron los teólogos eclesiásticos, casi todos obispos. Hay que valorar como un gran acierto de la gran Iglesia colocar en el episcopado a un puñado de grandes intelectuales, que fueron también grandes cristianos y grandes pastores. Ellos dieron forma cabal a la primera teología cristiana.

En sus elaboraciones hay un matiz apreciable respecto de los laicos que reseñamos: para estos lo fundamental es expresar su fe de modo convincente a la razón 
ilustrada, teniendo en cuenta que para un romano lo ilustrado tiene que ver con el rigor, cuyo modelo es la retórica jurídica, mientras que para un helenista el paradigma es la filosofía, sobre todo el neoplatonismo. Así pues fue una teología con un tono muy personal, pero también sanamente apologética, ya que estaba elaborada con miras sobre todo a los cultos de su época que no eran cristianos. También tuvieron en cuenta la ilustración de la comunidad eclesiástica y, obviamente, la ortodoxia, pero la perspectiva fundamental era la de decirse satisfactoriamente a sí mismos el misterio cristiano y decirlo solventemente a las personas cultas.

Para los eclesiásticos dos eran las preocupaciones esenciales: el esclarecimiento y la defensa de la ortodoxia, y la edificación de la comunidad cristiana. La primera era perentoria porque como el cristianismo era religión pública oficial, el gobierno necesitaba tener claro qué culto era el legítimo, porque en ofrecer públicamente el culto legítimo se jugaba la protección de Dios al imperio. La segunda venía dictada por su oficio, por su preocupación pastoral. Hay que decir que los grandes obispos vivieron estos diversos requerimientos desde una unidad de fondo que da grandeza a su teología: el convencimiento de que la verdad del cristianismo era saludable, tanto para su comunidad como para la salud pública.

En la edad media los letrados son cada vez más, no los obispos sino los monjes y después los frailes. Los teólogos fueron Anselmo, los victorinos o Bernardo de Claraval, y desde el siglo XIII Tomás de Aquino, Buenaventura, Scoto y posteriormente Occam.

Desde el siglo XII con Abelardo comienza a darse un giro que tendrá mucha importancia hasta hoy: la pertenencia de la teología al mundo académico y por tanto la configuración de una epistemología en la que cada vez va llevando más la voz cantante la formalización rigurosa, la lógica interna, tanto en el planteamiento como en la argumentación, así como la presentación del estado de la cuestión con la discusión de los argumentos de todos los que se habían ocupado del tema. Es verdad que en los más grandes, es el caso paradigmático de Tomás de Aquino, todavía estará presente la unción de la fe y las preocupaciones de fondo de las personas y la sociedad de su época, así como también el respeto por la Sagrada Escritura. Pero a la larga lo académico del método, es decir, la formalización de lo que se produce y la referencia cada vez más excluyente a la propia academia, será lo que exija mayor atención y se lleve las mejores energías. Y así, lo que comienza siendo una exigencia de rigor ante la razón ilustrada, acaba por vaciarse de referentes vivos y se convierte en un saber esotérico e intrascendente para el pueblo de Dios y la marcha de la historia. Por eso en la baja Edad Media la teología decae y entra en el siglo XVI bajo la égida del nominalismo y el positivismo teológico.

En esta época tienen una relevancia teológica especial las mujeres. Ya en el siglo XII la abadesa Hildegarda de Bingem constituye un ejemplo preclaro de creatividad, versatilidad y unción. Pero tenemos que esperar a la segunda mitad del siglo XIII y al siglo XIV para que una pléyade de mujeres renueven el hablar creyente y disciplinado sobre Dios, que en su tiempo no fue considerado teología, pero que ciertamente lo es con muchos más méritos que la casi totalidad de la que en su tiempo se consideraba tal. Nos referimos a mujeres como Ángela de Foligno, Catalina de Siena o Hadewijch. Desgraciadamente los confesores de Catalina no le tuvieron respeto y volcaron sus mensajes en su propio paradigma escolástico, por lo que 
no es fácil distinguir lo de ella de lo de ellos. A pesar de eso, es posible encontrar doctrina sólida y sistemática. Más fortuna tuvo Ángela que en su Libro del amor de Dios, se revela con una gran finura analítica a la vez que con una capacidad excepcional para nombrar rigurosamente el contenido teologal y antropológico de experiencias-límite. Lo mismo podemos decir de Hadewijch, cuyas formulaciones henchidas, límpidas y muy audaces dan que pensar y materia muy rica para discernir.

Frente a la formalización tardoescolástica, cuyo doctrinarismo reducía al mínimo el contenido experiencial y sacrificaba al sistema la historia viva de la revelación, de la que el teólogo tiene necesariamente que participar, estas mujeres anticipan el giro antropológico de la modernidad ya que sus libros no se reducen a dar cuenta de meras facticidades sino que son rigurosa fenomenología y por eso presentación del misterio cristiano a través de su participación en él, distinguiendo claramente el acontecimiento de lo que en él reluce, aunque sin separarlo, porque el cristianismo es para ellas acontecimiento o, más complexivamente, historia viva.

Estas mujeres fueron laicas, aun con la especificidad de ser beatas o beguinas, que era la única posibilidad que les quedaba a las mujeres de vivir responsablemente su libertad. El precio fue muy caro, pero lo pagaron fecundamente: tuvieron que disfrazar su teología de no teología y su saber en declaraciones de ignorancia. En esto fue maestra posteriormente Teresa de Ávila, que tiene pretensión y conciencia de escritora y aun de maestra en el espíritu y que gasta muchas horas en formular lo más adecuadamente su doctrina, que se alimenta de libros (es sintomática su protesta por la publicación del Índice de libros prohibidos en el que estaban la mayoría de sus fuentes, incluida la Escritura), y que sin embargo para distraer la censura repite incesantemente que es mujer y ruin y que por tanto lo que escribe no tiene ninguna pretensión, más aún que se reduce a mera materia para que los que saben examinen su camino.

Al abrirse el siglo XVI nos topamos con un capítulo altamente sintomático y premonitorio, más aún central, del tema que estudiamos: se trata de los humanistas cristianos, es decir, gentes de saber, impregnados de la cultura clásica, en la primera línea de las preocupaciones de su tiempo, pero sobre todo cristianos, y, además, los más notables, amigos entre sí: Moro, Erasmo y Vives, un círculo internacional, verdaderamente católico, ecuménico, más aún cristianamente fraternal. Ellos se sentían consagrados, primero a vivir la congruencia cristiana en una sociedad que casi lo hacía imposible ya que, tanto del lado eclesiástico como más aún del civil, exigía servidumbres incompatibles con la libertad cristiana; pero desde esa entereza, la parresía, que en su caso se disfrazaba de discreción y elegancia, se sabían llamados a un apostolado intelectual, lo que se traducía concretamente en esclarecer el seguimiento de Jesús, es decir, el modo de ser plenamente humano desde el paradigma de Jesús en su circunstancia concreta. Para eso aunaron el conocimiento de primera mano de la Escritura y la inmersión real, consciente y comprometida en su época.

Esta especie se extinguió a medida que los absolutismos en boga negaron el espacio para que floreciera. Es sintomático que Moro muriera como campeón de la libertad cristiana, como representante eximio de lo que para el cristianismo es un sujeto humano: alguien que vive su autonomía responsablemente, es decir como respuesta a la propuesta de Dios revelada en Jesús de Nazaret y vivida en la Iglesia. No hay en su posición nada de heteronomía: sus críticas al lastimoso estado de la 
institución eclesiástica y a las pretensiones desmedidas de la curia papal fueron constantes, lo que no obstó para coincidir con su veredicto, que era el de su conciencia y representaba la genuina tradición, que no podía ceder a la voluntad del que podía imponerla por la fuerza. Otro tanto podemos decir de Erasmo: permaneció siempre en la Iglesia católica, pero sin alinearse a lo que sentía como mera política eclesiástica que solo sabía negar el error confiscando el pensamiento y unciendo a los cristianos como súbditos a príncipes católicos tan absolutistas como los otros. Su defensa de la libertad cristiana, libertad inherente al humanismo cristiano, encontró un gran eco, incluso en prelados muy eximios, pero a la postre fue condenada, aunque no su persona. Otro tanto podemos decir de Vives, que debió andar fuera de su tierra, que con los Reyes Católicos se había embarcado en una cruzada insensata por la limpieza de sangre y que, a pesar de que el emperador, liberal en este punto, le prometió protección, prefirió vivir su libertad como peregrino.

Quiero insistir que en los tres casos no se trató meramente de la defensa del individuo frente a instituciones absolutizadas en nombre del cristianismo. Esa causa ya sería muy noble. Pero en su caso se trató concretamente de la libertad cristiana que presupone la obediencia absoluta a Cristo, obediencia vivida en la Iglesia, pero que no equivale sin más a la obediencia a la institución eclesiástica, y que por eso se empeña en distinguir cuándo actúa como servidora de la comunidad cristiana con el espíritu dado a su oficio y cuándo lo hace movida por la lógica institucionalista que tiende a absolutizarse, como ocurrió con los representantes legítimos de la religión revelada al condenar a Jesús.

No podemos decir que Ignacio de Loyola fuera un intelectual, pero tenía de común con los tres citados que, tras su conversión, sintió que pertenecía a la gracia que se le había dado y a la misión que se le había encomendado, el ayudar a las almas con su conversa y más aún dándoles los ejercicios espirituales que él había experimentado con tanto fruto. También coincide con ellos en la necesidad que siente de escribir lo que va viviendo, formalizándolo para hacerlo comunicable. Como ellos, para hacerse más apto, siente que debe estudiar. Pero tanto en Alcalá como en Salamanca se le impide tener esas conversas, que él creía propias de su vocación. La argumentación del dominico que lo pone preso en Salamanca indica el fondo de la cuestión: Le plantea el dilema del origen de su saber sobre Dios y la vida cristiana: "o por estudios o por Espíritu, atqui no por estudios...". Por Espíritu equivalía según el fraile a la condición de alumbrado, que tenía como pena la hoguera. Quedaba excluida la experiencia espiritual, realizada por supuesto en la Iglesia, como fuente de comprensión del misterio cristiano, y quedaba más negada todavía la posibilidad de que un laico se dedique a comunicar su fe. Ambas tareas quedan reservadas a los clérigos letrados. Es interesante que Ignacio se someta, pero protestando que no acepta la sentencia porque cree que vulnera su libertad cristiana, que era respuesta a su vocación. Como a él le parecía irrenunciable su vocación de ayudar a las almas y se le negaba esa posibilidad siendo laico, decide ir a París para estudiar, es decir, implícitamente para hacerse clérigo.

El caso de Ignacio de Loyola es el preanuncio de lo que será el pos-Trento: a pesar de que se seguía proclamando que la Iglesia era la congregación de los fieles cristianos, el sujeto real de la Iglesia será la clerecía. Ella será la Iglesia docente, en tanto que los simples fieles quedarán reducidos al papel de Iglesia discente, cuyo 
único derecho será el de ser apacentados por sus pastores, teniendo presente que en el alimento proporcionado por ellos solo debían entrar los rudimentos de la fe, pues como decía elocuentemente el catecismo "doctores tiene la Santa Madre Iglesia que os sabrán responder". Queda rotundamente negada la posibilidad de que los laicos sean teólogos.

No puede ocultarse el hecho de que tras Trento la Iglesia católica cayó en una suerte de monofisismo eclesiástico, y la consecuencia de negar la sustancia y autonomía responsable de los fieles cristianos fue que la misma institución eclesiástica fue perdiendo sustancia hasta casi vaciarse. Es palpable el desierto pavoroso de teología y más en general de pensamiento cristiano en los siglos XVII y XVIII. El monopolio eclesiástico se convirtió en rutina y desuso. Por eso los pensadores cristianos de esta época fueron lo que podemos calificar de laicos por la libre, cuyo símbolo sería Descartes, Pascal o Leibniz, para no hablar de Rousseau.

Ya en el siglo XIX cuando todo el pensamiento vivo se desarrollaba en las lenguas modernas, la teología se empeñó en conservarse no solo en latín sino en las mismas estructuras formales de la edad media. Era un síntoma de la cerrazón a pensar la historia presente a la luz del acontecimiento escatológico cristiano, disfrazada de defensa ante un mundo que se edificaba contra Dios. Es obvio que los pocos libros vivos de la época como Las cinco llagas de la santa Iglesia de Rosmini o la Simbólica de Möller se escribieron en las lenguas de sus países, pero no es menos sintomático que la obra de Rosmini fue condenada por el Santo Oficio y la escuela de Tubinga, desautorizada.

En el siglo XIX no creo que haya nadie que merezca el nombre de teólogo con más justicia que Dostoievski. Naturalmente que fue un novelista: escribiendo historias se ganó miserablemente la vida y las escribió con pasión y maestría inigualables. Pero mucho de lo que tenía más en el corazón y planteó con toda honradez, con toda lucidez y con corazón cristiano eran problemas teológicos: El problema de una intelligentsia que se cierra a Dios, no solo a la institución eclesiástica sino a Dios, o por lo menos al Dios recibido, el problema no menos de la plausibilidad de un staretz, con su conmovedora grandeza humana en esa época, y no menos el problema de si es posible encauzar cristianamente las pasiones humanas (Los hermanos Karamazov); o la cuestión del corrimiento imperceptible de la autonomía inherente a la dignidad de la persona humana a la autarquía deshumanizadora y criminal, y el papel de la conciencia (Crimen y castigo); o, todavía más a fondo, el problema de la cristología, el problema de la viabilidad humana del paradigma grandioso de Jesucristo (El Idiota).

No dudo que en esos siglos, hasta bien entrado el siglo XX, mucha gente alimentó su mentalidad y vivencia cristiana en literatos. Por ejemplo, ¿quién ha dicho con mayor plausibilidad y hondura que el amor del amante lleva realmente al amado, tesis central cristiana, ya que la premisa mayor del cristianismo es que Jesús nos lleva realmente en su corazón, que El Fausto de Goete, Don Juan Tenorio de Zorrilla y sobre todo Peer Gynt de Ibsen? Habría que citar a Cervantes, Calderón, Corneille y Racine, Novalis, Chateaubriand y Lamartine y hasta Hugo, para no hablar de Gogol o, posteriormente, Péguy. También, filósofos como Schleiermacher o Kierkegaard o los socialistas utópicos que no solo se aprovecharon de la figura de Jesús para sus prédicas sino que descubrieron aspectos medulares de su empeño profético por el Reino, que estaban siendo dejados de lado por la ortodoxia. 
Como pasó con la escuela de Tubinga en el XIX, en la primera mitad del siglo XX fueron condenados los intentos de decir el cristianismo a la altura del siglo; y fueron condenados por una institución que no se daba cuenta de que la mayor infidelidad es ser insignificante, es decir, no decir nada a sus contemporáneos por absolutizar un lenguaje anacrónico y lo que es peor por ser ella misma anacrónica ya que el lenguaje no es sino la expresión de una situación vital. Es cierto que hubo teólogos realmente intrascendentes ya que la adaptación a la época era tal que equivalía a su absolutización y consiguientemente a la relativización cristiana; pero otros hablaban a la época desde la trascendencia cristiana. Todos fueron condenados en nombre de una teología muerta. En el caso de los laicos que nos atañe particularmente es significativo el silencio obsequioso al que se redujo Blondel, aunque su influjo fue fecundo y duradero.

Gracias a Dios, la audacia de un papa realmente pastoral convocó un concilio para decir de nuevo el cristianismo. Era un anciano que desde su juventud había visto claro que no bastaba con que un sacerdote fuera bueno, porque para no hacer despreciable su ministerio era imprescindible que fuera instruido. Este papa echó atrás los esquemas restauracionistas de la curia vaticana y puso en marcha a la Iglesia para elaborar otros que comunicaran realmente el misterio al mundo contemporáneo de modo que este pudiera reconocerlo como buena nueva. El retraso era tan grande, la incomunicación tan espesa y la inadecuación de los instrumentos de tal calibre que el Concilio necesitó cuatro años para elaborar sus esquemas, y al fin, cuando todo andaba ya empistado, comprendió que no había hecho sino poner en marcha un dinamismo y plantar un horizonte, pero que su labor tenía que considerarse solo (y también nada menos) que el punto de partida para recrearlo todo.

El postconcilio coincidió con un cambio muy fuerte de horizonte que luego se ha visto como la maduración y consumación de una época, que daría lugar, una década después, al surgimiento de otra nueva época. Era lógico que, tras el deshielo teológico provocado por el concilio y los nuevos fermentos epocales, las elaboraciones teológicas no siempre fueran armónicas y maduras. El balance es muy positivo, pero los extremos, aireados por la prensa sensacionalista, provocaron en gente de poder la añoranza de ese tiempo en el que la institución eclesiástica controlaba férreamente todo. Y hacia esa ortodoxia fundamentalista van encaminando a la institución.

Por otra parte el postconcilio conoce la eclosión de la teología universitaria, que había comenzado a implementarse en la década de los cuarenta para superar el ensimismamiento escolástico, siguiendo el ejemplo, si no el modelo, de las facultades de teología reformada de las universidades del centro y norte de Europa. La asimilación de los métodos de las ciencias del hombre y particularmente de las hermenéuticas e históricas y de modo más general la penetración del rigor científico de las mejores universidades fue muy beneficiosa para la teología, tanto para la teología propiamente dicha como para las ciencias conexas o auxiliares como la exégesis y la historia de los dogmas y de la Iglesia.

Sin embargo, a la larga se han mostrado también serias limitaciones de este horizonte. Para decirlo de una manera simple, el claustro universitario es un verdadero claustro, como lo fueron los claustros monacales, como lo fue el de la institución eclesiástica cuando desde el pos-Trento se cerró sobre sí. Dos son las principa- 
les consecuencias: la primera el empeño absorbente por la formalización que no solo convierte la teología en una ciencia esotérica que no alimenta al pueblo de Dios ni evangeliza al mundo sino que se formaliza excesivamente, ocupando un lugar desmesurado las citas, las antiguas autoridades de la escolástica. Eso significa que la teología es en buena medida la recodificación incesante de lo ya previamente codificado, con desmedro de lo más importante, la intuición sensible, la experiencia del misterio. Se llega a olvidar que esa es la referencia primaria de la teología. Desgraciadamente en muchos libros la referencia casi absoluta son otros libros de teología. Con este método ¿puede darse algún avance? ¿No acaba convirtiéndose la teología en un saber muerto, como llegó a estarlo la neoescolástica?

Creo que la historia de la Iglesia da que cuando la teología se deja en manos de los hombres de la institución o de los especialistas acaba volviéndose insignificante o intrascendente, extremos que a la larga vienen a ser lo mismo. Esta apreciación no significa en absoluto la desautorización de la injerencia eclesiástica en la teología o del formato universitario de la teología. Ambos son imprescindibles. Pero cada vez más se muestran como insuficientes. El papel de maestros de la fe de los obispos y el de confirmar en la fe de los sucesores de Pedro son servicios imprescindibles en la Iglesia. Lo mismo que perdería mucho la teología si se la echara de la universidad, es decir, si se prescindiera de su rigor científico y de su diálogo con las demás disciplinas universitarias, así como de su libertad de investigación. Pero hay que decir resueltamente que cada día se echa más en falta el aporte de los laicos. Me refiero a los laicos no graduados de teología en las universidades, porque los graduados, los laicos profesionales de teología, cada vez son más y en no pocas universidades son ya mayoría, incluso, cada vez más, las laicas.

\section{RAZONES POR LAS QUE LOS LAICOS NO HAN SIDO TEÓLOGOS}

¿Por qué los laicos hasta ahora no han sido normalmente teólogos? Hay dos razones de peso, ligadas entre sí. La primera, de índole eclesial, es la identificación práctica entre Iglesia e institución eclesiástica. Esta malformación gravísima de la Iglesia estaba tan consustanciada en los eclesiásticos que el esquema sobre la Iglesia que la curia preparó para el concilio Vaticano II contemplaba un capítulo sobre la jerarquía y otro sobre el pueblo de Dios. La Iglesia era obviamente la jerarquía y el pueblo de Dios, los fieles, que según la formulación de Pío X no tenían más derechos en la Iglesia que el de ser regidos por sus pastores. En la sensibilidad de no pocos eclesiásticos y en buena medida en el derecho canónico, así sigue siendo todavía. Sin embargo, la afirmación del Concilio de que el pueblo de Dios está formado por la jerarquía, los religiosos(as) y los laicos, y que todos en la Iglesia tienen la misma dignidad, más aún que todos deben llevarse mutuamente en su fe, en su amor fraterno y en su vida cristiana, tiene una trascendencia indudable y se va abriendo poco a poco camino. La conciencia de la jerarquía, y no menos de los laicos, de que todos en la Iglesia tienen la misma dignidad, que todos somos la Iglesia, es sin duda requisito indispensable para que los laicos puedan hacer teología con normalidad, no como casos excepcionales que confirman la regla de su exclusión de esta dedicación. 
La segunda razón tiene que ver con la división estamental de la sociedad, pacíficamente aceptada por la Iglesia. Cuando la jerarquía fue asimilada a los órdenes en el imperio romano y ella lo aceptó, cuando en la edad media pasó a constituir el estamento de los que oran, privilegiado, como el de los que luchan, respecto de la masa de los que trabajan, cuando en la sociedad señorial los obispos fueron señores, el señorío eclesiástico, y los párrocos eran dignidades, es obvio que el pueblo llano, que era cristiano, no tenía derechos o por mejor decir prerrogativas, no tenía, por ejemplo la prerrogativa de lo intelectual. Así lo decía la última pregunta del catecismo, que citamos arriba, elaborada, por supuesto por clérigos, "no me lo preguntéis a mí, que soy ignorante; doctores tiene la Santa Madre Iglesia que os sabrán responder”. Este ignorante por definición no podía convertirse nunca en teólogo.

Cuesta aceptar que la institución eclesiástica conviviera pacíficamente con esta situación, que la encontrara natural, y que por eso no trabajara en su transformación. La situación cambió, pero no por razones pastorales sino por la democratización de la sociedad, proceso resistido fieramente, como contrario a los designios de Dios, por la institución eclesiástica. La democracia política fue consecuencia del ascenso de las masas, ascenso conquistado por ellas en el campo laboral, educativo, de salud, de seguridad social, no menos que en el político. Hubo una minoría muy significativa de intelectuales que apoyaron este ascenso y catalizaron esta lucha. Hay que reconocer que una minoría de eclesiásticos sí apoyaron, incluso muy eficaz y creativamente, el ascenso en las condiciones de vida, sobre todo en educación y salud, pero las reticencias fueron casi universales en cuestión de sus derechos políticos, civiles y laborales. Durante demasiado tiempo el paradigma de la institución eclesiástica para la sociedad fue el organismo vivo que combina la desigualdad de funciones con la referencia mutua. Se puede decir que solo después de la Segunda Guerra Mundial aceptó la Iglesia lealmente la democracia, y la aceptó en parte por la mediación de los partidos socialcristianos, que si no controlaba por lo menos sentía afines, en parte por la presión de los obispos estadounidenses. Esta aceptación es indudablemente una de las bases para la formulación que hizo el Concilio de la igualdad de todo el pueblo de Dios en la Iglesia.

Pues bien, el ascenso de la masa a la educación básica y cada vez más a la media y el que no sea tan infrecuente su participación en la educación universitaria es uno de los requisitos indispensables para que el laico pueda ser teólogo como cosa normal.

\section{TRES EXPRESIONES EN CIERNES DE LA TEOLOGÍA LAICAL}

Tenemos, pues, que decir que tanto desde el punto de vista de su legitimidad eclesial como de la indispensable capacitación humana, empiezan a estar dadas las condiciones para que los laicos puedan ser teólogos.

Por lo que respecta a América Latina tres parecen ser las direcciones en las que se va a desarrollar esta actividad: La primera, la que tiene el campo más abonado, es la de los solidarizados con gente popular en la línea de la pastoral que tiene su referencia en Medellín y Puebla y la de gente popular implicada como agente en esa misma pastoral. La segunda es la de laicos, ordinariamente de clase media baja o 
media media, enrolados en movimientos eclesiales. La tercera es la de profesionales que hacen estudios de teología, aunque no la ejercen profesionalmente. Vamos a referirnos a cada una.

Hay gente popular que lleva décadas viviendo su cristianismo a partir de la lectura orante de la Biblia, sobre todo de los evangelios, y de una lectura asidua de los signos de los tiempos, y reuniéndose en estructuras muy flexibles, signadas por relaciones horizontales y mutuas, tanto para alimentar su fe y dar testimonio de ella como para labores de concientización y organización popular. Estas personas han alcanzado una verdadera madurez cristiana: no solo tratan de vivir el cristianismo personalizadamente y dar testimonio de él sino que lo poseen reflexivamente; más todavía, poseen el hábito de pensar el misterio cristiano desde su situación, y su vida personal y la vida histórica a la luz de la fe. Están también acostumbradas a verbalizar sus reflexiones, a dialogarlas e incluso a componer textos conjuntos. Todo lo dicho es el caldo de cultivo para hacer teología. Algunas personas ya la van haciendo, pero oralmente o de modo fragmentario. No pocas de ellas tienen capacidad de formalización. Casi solo les falta proponérselo expresamente, es decir, hacerse cargo de esta posibilidad como tarea para ellas, y la disponibilidad de un tiempo algo denso para escribir las elaboraciones. Tal vez este último sea el problema mayor y más difícil de resolver, aunque no insoluble, sobre todo si hay ayuda grupal y de algún teólogo que tenga trato habitual con ellas y las respete. También podría pensarse en alguna ayuda pecuniaria de alguna organización eclesial ya que estas personas escriben lo que puede convertirse en subsidios para la Iglesia.

¿Qué sería lo característico de su teología? La teología experiencial y narrativa en el doble sentido de cómo se vive el cristianismo cuando no hay elementos para vivir y se lucha no solo por sobrevivir sino por vivir dignamente y por hacerse respetar, y de que Dios y Jesús afloran de esa experiencia. Es totalmente distinto hacer teología cuando la vida se puede dar por supuesta y se trabaja por vivir más cualitativamente y por ayudar a otros, que hacerla cuando el tema de la vida es que la haya y se lucha humanamente por vivir. En esta situación agónica, que hoy, a diferencia de otras épocas, es siempre expresión del pecado del mundo, muchos pasajes del Evangelio suenan digamos que al pie de la letra, con una tersura y profundidad inigualables, con una exigencia total, pero también con un ofrecimiento de gracia que estremece. Una teología desde esta situación vivida ante Dios posee una densidad que no se puede procurar de otro modo. Por eso esa teología hecha por pobres con espíritu, es decir, por pobres que han recibido el Evangelio de que el Reino es para ellos y han creído en él y por eso son felices en medio de su lucha incesante por la vida propia y ajena, es un don más allá de toda medida para la Iglesia. Pero esta teología no puede suscitarse artificialmente, mediante un buido paternalismo, que la desnaturalizaría. Se precisa un proceso largo y complejo de creación de condiciones de posibilidad para que surja como una decisión y tarea personal y como algo aceptado y aun requerido por el medio.

Hay personas que llevan muchos años en movimientos eclesiales y en ellos han dado lo mejor de sí; han asimilado sus propuestas y son verdaderos agentes de ellas, a veces dirigen esos movimientos o introducen a otros a ellos. Con los años han adquirido bastantes conocimientos del cristianismo como revelación histórica que es y más aún de la vida cristiana, es decir, de lo que podemos llamar espiritualidad y 
pastoral. Son personas acostumbradas a verbalizar lo que poseen y tienen escritos guiones o incluso desarrollos de lo que proponen, que incluye también experiencias reflexionadas. Estas personas disponen de más tiempo que las anteriores para la formalización teológica y por otra parte puede haber una demanda más clara para sus elaboraciones. Tienen experiencia de un modo de vivir la eclesialidad bastante comunitario con expresiones simbólicas a veces muy expresivas y con actuaciones en la vida exigentes y progresivas que van construyendo a las personas y configurando ambientes. Tienen, pues, materia concreta para hacer teología.

El problema de estos cristianos para constituirse en teólogos es que el esquema en que se ha desarrollado su experiencia cristiana es a partir de itinerarios en los que el guión es fijo (tanto las actividades como los contenidos) y por tanto de lo que se trata es de actuarlo. En los movimientos las relaciones suelen ser intensamente afectivas, pero, en ese clima de mutua confianza, los papeles están ya señalados: unos enseñan y otros aprenden, unos dirigen y otros son dirigidos. Si lo que se propone a la persona es asimilar lo dado, vivirlo y trasmitirlo, no hay mucho margen para la vivencia y elaboración realmente personal. La teología a que pueden dar lugar los movimientos es una teología de escuela; en ella no se distingue la marca propiamente laical, aunque sean laicos todos los responsables.

No ha sido normal en América Latina que laicos profesionales estudien teología. Como fenómeno social es completamente nuevo que gente que no piensa ejercer de ningún modo la profesión de teólogo y que incluso no desempeña ningún puesto en lo que podemos llamar apostolado organizado, estudie seriamente teología, la estudie a pesar de sus muchas tareas, la estudie por imperativo de su ser cristiano, por el gusto de penetrar en el misterio cristiano que quiere vivir responsablemente. Es lo que está comenzando a pasar en nuestra América.

El sentido preciso de este estudio es el de constituirse en intelectuales cristianos: es decir, personas que son capaces de entablar de modo solvente un diálogo interno entre sus especialidades y su condición de cristianos, o más profundamente, personas que quieren que su cristianismo esté a la altura de su desarrollo intelectual y humano para que lleve la voz cantante en su vida privada y pública. Una característica de estas personas es que buscan con toda asiduidad convertirse en verdaderos sujetos humanos: personas cuya vida brota de sí, no por autarquía sino por autonomía responsable, es decir, personas que no se definen como miembros de conjuntos, determinados por sus reglas de juego, sino por el uso de su libertad liberada. Por esta razón, siendo personas que viven pacíficamente su cristianismo en la Iglesia, ayudando y siendo ayudados por otros cristianos, sin embargo no son lo que se dice gente de Iglesia, es decir, amoldadas por la institución eclesiástica.

Creemos que estas personas están especialmente capacitadas para hacer teología, si evitan el peligro de hacer la competencia a los voceros de la Iglesia o a los teólogos profesionales, y se mueven en su campo de cuestiones fronterizas entre el cristianismo y los campos de la experiencia humana en los que son especialistas y más en general entre cristianismo y cultura, cristianismo y vida o, también, en apreciaciones sobre lo que es ser cristiano desde su inserción en la historia humana, un campo bien amplio por cierto y apasionante. Un campo, por otra parte, que contempla expresamente el Concilio: "A la conciencia bien formada del seglar toca lograr que la ley divina quede grabada en la ciudad terrena (...) No piensen que sus 
pastores están siempre en condiciones de poderles dar inmediatamente solución concreta en todas las cuestiones, aun graves, que surjan. No es esta su misión. Cumplan más bien los seglares su propia función con la luz de la sabiduría cristiana y con la observancia atenta de la doctrina del magisterio" (GS 43).

\section{LA CUESTIÓN DE LA EPISTEMOLOGÍA TEOLÓGICA}

Si la única epistemología teológica es la académica, es claro que los laicos no pueden hacer teología: no tienen el método, y en el caso de universitarios de otras disciplinas que sí tienen el método universitario en sentido general, no tienen la preparación científica adecuada. Desde la teología académica los laicos son realmente legos, es decir, los ignorantes por definición, del catecismo. Por eso la pregunta es si no existe otra epistemología.

En la mayoría de los ambientes parece darse por supuesto que teología y teología académica son la misma cosa; lo demás será algo piadoso o impresionístico o a lo más ensayístico, algo que en un sentido muy genérico podría llamarse teología, pero que no acaba de serlo por falta de los requerimientos metodológicos: conceptualización rigurosa, conocimiento solvente del estado de la cuestión, es decir, de los que han estudiado el tema, de los argumentos básicos que se han barajado, de los puntos en los que hay consenso, de las cuestiones disputadas, de las intervenciones del magisterio, conocimiento de lo que la Escritura dice sobre el tema, y más en general del horizonte o los horizontes en el que se mueve la cuestión, tanto en la Escritura como en la historia de la Iglesia, como en la actualidad. Y, por supuesto, claridad y consecuencia lógica en la manera de exponer, de argumentar y de concluir.

El presupuesto del método es que los investigadores constituyen una comunidad virtual y que por tanto el saber es acumulativo, lo que presupone que se está a la altura de la cuestión que se quiere abordar o que uno antes de dar su aporte debe ponerse al tanto del punto en el que se está.

El presupuesto de esta manera de hacer teología es que el saber teológico es un saber susceptible de ser formalizado, es decir, de ser completamente objetivado y de estar por tanto a disposición de cualquier miembro de esa comunidad científica, que por hipótesis es abierta. Solo así el saber es realmente acumulativo.

Esta manera de hacer teología parece más apta para recodificar lo codificado que para codificar lo no codificado. Al recodificar lo codificado todos los datos están sobre la mesa; se trata de entenderlos mejor, tanto en sí mismos como descubriendo cómo se interrelacionan, qué matriz o construcción componen, o situándolos más adecuadamente en la época en que surgieron y en la nuestra, o relacionándolos con otros temas para ver qué puesto ocupan en el conjunto. Todo esto es sencillamente necesario. Por eso es imprescindible este modo de hacer teología. Pero también tenemos que tener conciencia de sus límites. De este modo se puede comprender mejor lo que ya se posee, pero no se puede llegar a comprender lo que no se posee aún.

Si el cristianismo es una revelación clausurada, un depósito que se dio a la Iglesia jerárquica para su custodia e interpretación, aunque también para su estudio 
incesante, es cierto que este tipo de teología es la teología sin más, siempre que se atenga, por supuesto, a las indicaciones del magisterio. Pero si la primacía en la teología la tiene la actualidad, porque solo desde la participación en el movimiento actual del Espíritu es accesible desde dentro la revelación, lo decisivo será captar lo que el Espíritu dice a las Iglesias y hacia dónde mueve al mundo, ya que solo desde la pertenencia a ese movimiento trascendente las fuentes cristianas dejan de ser mera arqueología y se abren como revelación saludable. Pero no solo eso, solo desde la obediencia a la acción del Espíritu puede establecerse la correlación actual del seguimiento, que consiste en tener una posición equivalente en nuestra situación a la que Jesús de Nazaret tuvo en la suya. La teología tiene que decir a Cristo a su mundo, no, ciertamente, como parénesis, pero sí como dar razón de lo que creemos, vivimos y esperamos. Ha de decirlo hoy, a este mundo. Esto no quiere decir únicamente que ha de tener en cuenta el horizonte cultural al que se dirige, sino más internamente que ha de ser capaz de percibir la actuación del Espíritu en esa cultura. Esto significa que en cada cambio cultural la teología ha de recodificarse, en fidelidad a la revelación, por supuesto, pero no menos en fidelidad al movimiento del Espíritu en esa época y situación concreta.

Desde este punto de vista, que es el primario para una teología viva, el claustro universitario, en cuanto claustro que es, es un inconveniente para hacer teología; lo mismo que el confinamiento en la lógica institucional del que pertenece a la institución eclesiástica. Y en cambio la encarnación del laico, más aún si su encarnación es, como la de Jesús, kenótica, es una ventaja indudable. No decimos que el laico es el que tiene la exclusiva de la encarnación en la Iglesia. Todos los discípulos de Cristo están llamados a hacer suyas las alegrías y esperanzas, las tristezas y angustias de sus contemporáneos, sobre todo de los pobres y de los que sufren. Pero es claro que los laicos que trabajan, forman familia, intervienen activa y responsablemente en la vida ciudadana y política, y que llevan a cabo todas estas actividades como ejercicio de su vocación cristiana, están en condiciones más plenas que las de los miembros de la institución eclesiástica para asumir desde dentro la época y para percibir desde dentro por dónde pasa el Espíritu en ella y qué es lo que se le opone como pecado del mundo.

El problema fundamental del teólogo laico es precisamente el de cómo vivir esta inmersión en el mundo sin ser del mundo, porque los mecanismos de presión en esta sociedad de totalitarismo de mercado son tan violentos y están tan diseminados, tanto en forma de compulsión por seducción como por exclusión, que lo normal es quedar reducido a la condición de miembro de conjuntos que recibe de ellos tanto las posibilidades de vida como las condiciones y límites. El problema actual del laico es el de llegar a ser verdadero sujeto: vivir las relaciones sociales con verdadera libertad espiritual, es decir, absolutizando las personas (divinas y humanas) y relativizando todo lo demás. Solo en esas condiciones cabe la encarnación, que no consiste en ser uno de tantos sino en relacionarse con los demás personalizadoramente, y más aún la encarnación kenótica, que es propiamente la encarnación cristiana (LG 8). Este problema lo tiene también el teólogo que pertenece a la institución eclesiástica y el profesor de universidad, ya que como ambas corporaciones son en América Latina ámbitos privilegiados que luchan por mantener sus privilegios, tienen el grave peligro de identificarse con la lógica institucionalista y rechazar de 
hecho macizamente la posibilidad de compartir las angustias de la mayoría de la población y más todavía de echar la suerte con ella.

\section{REQUERIMIENTOS AL LAICO PARA QUE PUEDA SER TEÓLOGO}

El único problema que pueden tener los laicos que no se han graduado de teología en la universidad para hacer teología es la falta de conocimiento de la Tradición. Esta dificultad se vuelve imposibilidad si no tienen algún conocimiento de la Biblia y un conocimiento suficiente de los evangelios. En efecto, el cristianismo es revelación histórica y lo histórico no se conoce por intuición o revelación de lo alto sino que, como dice Pablo, entra por el oído, es decir, tiene que ser comunicado por algún testigo. Esta comunicación tiene dos aspectos: conocimientos objetivos de los acontecimientos y comunicación desde dentro, es decir, con el peso revelatorio que contienen. A esto último aludía Pablo a los corintios cuando les decía que no ha querido predicar el Evangelio con discursos persuasivos sino con la fuerza del Espíritu. Esto último es imprescindible, pero insistiendo complementariamente que el Espíritu es el de la Palabra, una palabra con significado y sentido, en lo que insiste en la misma carta con mucha fuerza. Es decir que el Espíritu es imprescindible, pero no suple nunca a la información, información que, por otra parte, no es ajena al Espíritu sino certificada por él.

La Iglesia es Tradición, es decir, trasmisión hasta hoy de lo que viene de Jesús, llevada a cabo por testigos con la prestancia de Jesús. Ya hemos insistido que el Espíritu no se comunica al margen de la encarnación kenótica. Ahora tenemos que insistir complementariamente que tampoco actúa al margen de la Palabra, que él es el que lleva, como declaraba Lucas respecto de su trabajo de hagiógrafo, a investigar lo que dejaron escrito los que escucharon a los testigos de la primera predicación de los discípulos del Crucificado resucitado y a compulsarlo cuidadosamente y a componer una narración ordenada. El teólogo precisa de este conocimiento porque no puede establecer la nueva correlación del seguimiento si no conoce tanto la relación de Jesús respecto de su situación como la de la Iglesia primitiva respecto de las suyas. También es conveniente que conozca las distintas correlaciones de la Iglesia a lo largo de la historia. Pero las dos primeras son absolutamente imprescindibles.

Que conozcan los testimonios sobre Jesús y las elaboraciones de la Iglesia primitiva consignadas en el Nuevo Testamento, con sus referencias al Antiguo, no significa que sean especialistas sino que hayan recibido suficientemente esta tradición, lo que puede obtenerse por la lectura orante comunitaria prolongada, si fue hecha con buen método.

Si se da este conocimiento básico de las fuentes, y existe una vivencia cristiana seria y esta conlleva una actitud habitual de discernimiento, la condición de laico es una ventaja para hacer teología, aunque la falta de tiempo dificulte su adecuada formulación. Pero, si no hay prisa, si se va formulando al ritmo de los acontecimientos vitales, sin la presión de los requerimientos académicos, la teología puede ser de calidad.

Si el laico, además de vivir una vida encarnada, posee saberes sólidos en cualquier rama de la ciencia o el trabajo o algún aspecto específico de la vida, la 
teología puede ser mucho más densa y concreta. Si además vive su encarnación desde la opción preferencial por los pobres, tiene un acceso más profundo al misterio cristiano. Y si además de todo esto posee conocimientos básicos de la historia de la Iglesia leída teológicamente, es decir, desde el parámetro del Reino y el seguimiento de Jesús desde la acción del Espíritu en la historia, está en condiciones muy superiores a otros teólogos profesionales, que tienen condiciones profesionales superiores, pero con una incardinación vital menos densa.

\section{DE LA COEXISTENCIA A LA MUTUA FECUNDACIÓN DE LOS TRES MODOS DE HACER TEOLOGÍA}

Preveo que si la teología hecha por laicos llega a adquirir un volumen y una calidad considerables, variarán también, por referencia a ella, los otros modos, eclesiástico y académico, de hacer teología.

Por un lado se enriquecerán estas formas establecidas de hacer teología, llegarán a comprender realmente (y no solo nocionalmente) que la experiencia del misterio cristiano es el lugar donde se abre desde dentro la Tradición. Además tendrán mucho más en cuenta las cuestiones realmente vitales para la mayoría, y no solamente, como es el caso de la teología científica, el problema de la racionalidad, entendida además de un modo muy restringido, o la coherencia con el magisterio eclesiástico entendida de un modo muy reductivo, es decir, literal, como suele ser el caso de la teología eclesiástica. Será muy sano que la teología académica comprenda que la mera erudición puede ser realmente ciega al misterio, si no la dirige la experiencia, tanto personal como de la comunidad cristiana y más en general la experiencia del Espíritu en la historia. También lo será que la teología eclesiástica comprenda que la ortodoxia puede resultar insignificante y por eso radicalmente infiel, si se niega a medirse por el movimiento del Espíritu del Crucificado resucitado en la vida histórica y si no comprende que cada quien debe escribir a la medida de la gracia recibida.

Además, creo que la introducción de una tercera forma de hacer teología puede contribuir a sanear las relaciones entre la teología académica y la magisterial. Actualmente esas relaciones no son buenas, y creemos que hay culpa de parte y parte. Por parte de mucha teología académica, su confinamiento en el mundo académico y en la razón que rige en él llega a degenerar en una suerte de irresponsabilidad respecto del resto del pueblo de Dios y de sus contemporáneos no académicos. Ese confinamiento a veces está teñido de una cierta conciencia de superioridad respecto del vulgo y por tanto de elitismo. Creemos sinceramente que no está justificado y que más bien hay una incapacidad manifiesta para empatar con los anhelos más hondos de la gente y sus vivencias más medulares. Puede ser que la teología de los seglares les ayude a corregir esta óptica y a salir del claustro.

Por parte del magisterio hay propensión a lo mismo: a un confinamiento en la clerecía, que llega a ser una suerte de nomenklatura, y una dificultad muy honda para empatar con el sentir cristiano de la gente. Como en el caso de la academia, y peor, este confinamiento que es incapacidad e irresponsabilidad respecto de los requerimientos de su ministerio, está escondido a su conciencia por una manera 
errada de comprender su oficio de enseñar, que en la práctica parecería provenir de una ciencia infusa conectada con la ordenación y el cargo. Así, en vez de buscar con verdadera obediencia lo que el Espíritu dice a las Iglesias, creen poseerlo de antemano, confundiendo formulaciones anteriores con la regla de la fe. Al no sentir el apremio pastoral, la urgencia de comunicar el cristianismo como buena nueva para la gente concreta, se centran en investigar posibles errores y condenarlos. Puede ser que la teología de los laicos, volcada a dar razón de su fe, de su vida cristiana y de su esperanza, los estimule a orientarse más en esa dirección, poniéndose en actitud de búsqueda.

Puede ser también que, conscientes ambos de sus insuficiencias, traten de ayudarse mutuamente en vez de la prescindencia metódica de unos y la desconfianza sistemática de otros. La ayuda del magisterio a la teología académica debería consistir en indicar lo que desde su punto de vista es denso y medular en sus aportes y en usarlo, con parsimonia, pero teniéndolo realmente en cuenta; en alertar también de lo que les disuena expresando con toda franqueza las razones y más profundamente los motivos, pero manteniendo el clima de confianza y libertad cristiana. También puede colaborar el magisterio con los teólogos académicos proponiéndoles temas y perspectivas para estudiar. A este respecto hay que recordar lo fecunda que fue la colaboración en el Concilio, lo mucho que crecieron en ella unos y otros. Ahora se tiene la impresión de que ese es un coto cerrado y no propuestas abiertas.

La ayuda de la academia al magisterio debería consistir ante todo en recuperar su dimensión eclesial para que el magisterio pueda percibir que son un cuerpo eclesial, para que los capte como algo de dentro, para que vea que las diferencias y aun las críticas son realmente internas. Esto lo ha de tomar muy en serio la academia, incluso aunque tenga la impresión de no ser comprendidos ni valorados como hermanos en la fe con un carisma específico en la Iglesia. Por eso también ellos deben valorar lo que el magisterio hace bien e incluso usarlo, aunque la teología no sea una glosa del magisterio. También se debe exigir que las críticas al magisterio sean a hermanos en la fe, en quienes se reconoce deseo de acertar y solicitud pastoral. Han de ser críticas francas, pero, insisto, internas y fraternas. También deben ver los responsables actitud de colaborar, sin que eso equivalga a entenderse como intermediarios suyos. Es bueno que la academia ponga al descubierto los implícitos de las elaboraciones del magisterio, pero de modo que se vea que eso no equivale a su desautorización sino a su comprensión más profunda, tanto de lo que hay de evangélico como de lo que parece incompatible con él.

Creo que los intelectuales cristianos van a ser particularmente importantes tanto para que la academia se pregunte por la trascendencia de sus elaboraciones como para que el magisterio comprenda que su oficio es mucho más modesto, pero también más medular.

La labor de los teólogos populares tardará mucho más en ser reconocida porque la relación ilustrada impide hasta hoy reconocer que es verdad que el Padre ha encubierto el misterio del Reino a los sabios y entendidos y lo ha revelado a la gente sencilla. Este descubrimiento, sin embargo, es el de mayor envergadura, es decir, el de más trascendencia en el sentido más estricto de esta palabra, porque hasta que la Iglesia no se organice alrededor de los pobres con Espíritu no acabará siendo del todo la Iglesia de Jesucristo. 


\title{
RESUMEN
}

La teología laical tiene una larga historia. El autor del artículo recuerda cómo esta remonta a los orígenes de la teología y cómo, con sus altos y sus bajos, ha podido darse hasta nuestra época. La historia de la teología no carece de grandes teólogos dedicados a ella por completo. Lo que en este artículo más interesa es indicar diferentes maneras de hacer teología no profesional, en cada caso con su riqueza, su necesidad, sus límites y sus requisitos.

\begin{abstract}
Lay theology has a long history. The author of this article calls to mind how this theology goes back to the very origins of theology, and how, with it highs and its lows, it has been able to bear fruit right up to our own times. The history of this theology does not lack great theologians entirely dedicated to it. What most interests the author in this article is indicating different ways of doing non-professional theology, in each case pointing out its richness, its necessity, its limits and its requisites.
\end{abstract}

